\title{
Decorative Blown Glass in Interior Furnishing
}

\author{
Lingling Zhang \\ School of Humanities \\ Yantai Nanshan University \\ Yantai, China
}

\begin{abstract}
Glass art of interior decoration is to decorate and beautify interior environment of the building using glass artworks, so that modern blown glass may serve as a foil to the environment and make the finishing point in interior furnishing with graceful appearance and wide varieties, and keep up with fashion of interior environment, creating a certain atmosphere. The blown glass interior artistic furnishings are discussed in this paper from the perspective of characteristics of interior glass furnishings, of practical and decorative features and both of them, to the diversified tendency. It is expected that Chinese blown glass interior artistic furnishings will develop better with innovation.
\end{abstract}

Keywords-blown glass furnishings; sense of modern; innovation and development

\section{INTRODUCTION}

New demands have been generated for people's living rooms and basic necessities with the development of times and advancement of technology. The interior artistic furnishings of modern blown glass have entered into the room of modern life, becoming an indispensable classic element to beautify the living room and to create an environment. Blown glass art is a plastic art with a long history and a unique form of expression, which is the bridge connecting humanity and the environment. It has been used for interior furnishing in the evolution from tradition to modern and been widely used in space decoration with diversity ways of expression, giving full expression to material properties and formal sense of beauty of blown glass art, playing an important role in construction of human life and the ideal working palace.

Interior blown glass art lays particular stress on display and decoration, and its functions are mostly for watching by people, collection, beautifying the environment etc., thus increasing factors and requirements of art. At the mention of blown glass interior furnishings, we can easily think of such professional institutions as museums and art galleries. Under the background of today's increasingly developed modern social life, more and more non-professional organizations come to take a keen interest in blown glass interior furnishings, and relevant agencies are supporting many of the art industries.

\section{CHARACTERISTICS OF INTERIOR BLOWN GLASS ARTWORKS}

- Indoor blown glass artworks can not be compared with the large-scale outdoor glass sculptures in terms of sizes.

- The interior collection of public blown glass art has special requirements for light. In addition to natural light, some blown glass artworks also need bottom soft light and back hard light as the main light source with top light and the top side serving as auxiliary light source. Moreover, the original color of light source shall take cool light as the basis. Thus the mysterious feeling will be filled in the glass color. The light source of blown glass artworks have more stringent requirements for light source, and need more viewing angles.

- Glass materials are fragile, therefore, secure display mode is also one the elements that blown glass artworks are distinguished from other exhibits on display.

For example, the front desk of Kerry Centre Hotel is furnished with a set of blown glass works. Many large hotels have taken a keen interest in blown glass art and other emerging modern craftsmanship. And many exhibits in banquet hall are furnished with blown glass artworks, reflecting the new demands of culture and arts by the modern economic development.

Modern blown glass interior furnishings are not only directly affecting people's living quality, but also closely related to interior spatial organization and whether or not a high standard better environment can be created. Modern blown glass interior furnishings shall meet the basic requirements of people's living needs, rest and so on, but also shall comply with the aesthetic principles, to form a certain atmosphere and mood, bringing people the enjoyment of beauty. Accordingly, we have known that the basic types of blown glass furnishings are practical, decorative and the practical decorative type of both. The use of modern blown glass interior furnishings is very extensive. But the most worthy of our attention is to consider the impact on overall effect of the interior design, which is the key to select blown glass interior furnishings. In designing of artworks, their shapes and the positions to place them shall be determined, and the specific requirements of their theme and technique of 
expression shall also be proposed to reflect character and atmosphere of the space.

\section{SPECIFIC FACTORS FOR SELECTION AND ARRANGEMENT OF BLOWN GLASS INTERIOR FURNISHINGS SHALL BE CONSIDERED}

- Blown glass interior furnishings shall coordinate with the interior basic style and space functions of use.

- The form, size and color of blown glass interior furnishings shall agree with the size and color of interior space.

- The arrangement form of blown glass interior furnishings shall take the principle of ensuring smooth traffic in the interior space.

- The national characteristics and cultural characteristics of blown glass furnishings shall be taken into consideration. The selections of blown glass furnishings' national cultural characteristics by people in different regions with different professions and cultural levels are all not the same. It can be said that the selection of interior blown glass furnishings' national cultural characteristics can best reflect the owner's personality traits and spiritual connotation.

The design of modern interior blown glass furnishing artworks shall also take the advantage of modern scientific and technical means, but its ultimate aim is always to create and design people's life. "All the designs are peopleoriented" is the eternal topic in the design industry. The interior environment created by people will be inevitably related to the quality of indoor living and production activities directly, and related to people's safety, health, efficiency, comfort and so on. The creation of interior environment shall take securing safety and conducive to people's physical and mental health as the most important prerequisite for interior design. Thus to guide people to build a better, newer modern science and technology as well as the modern personalized lifestyle, and to constantly coordinate the relationship between human beings and different types of the environment.

\section{MAJOR EMBODIMENTS OF THE DECORATIVE FORMS} AND APPLICATION FUNCTIONS OF MODERN BLOWN GLASS ART

- Decorative: Modern blown glass art takes morphology sculpture and varied vessel shapes as its main form which is different from the flower implements or other utility-type implements used for general furnishings, and it is the product of perfect combination of artistic ideas and glass material. Spatial environment and the artwork set each other off, and contrast with each other in terms of material, color, shape beauty, interior furnishings and lighting, to jointly create a culture of taste and sense of fashion in the room and provide a poetic space for people to rest the body and mind.
- Science and Technology: The blown glass craft has a long history, and its process technology is continuously innovated by science and technology making its materials be increasingly enriched. It has been applied to artistic creation and architectural design construction by many artists and designers, and new design forms, expressive themes and techniques have been introduced constantly. In recent years, the United States, Britain, Italy, France and Finland that have a profound foundation of culture and art as well as glass manufacturing tradition, have taken glass as an artistic creation carrier with an achievement of a very high level in the application. It can be integrated and penetrated with other materials, forming a diversified design look, making science and technology as well as art aesthetics find a perfect combination point in the bright glasses.

- Creativity: Blown glass craft is a catalyst to promote the traditional design concepts to develop towards modern design concepts. Traditional blown glass furnishings are mainly to meet the using function, yet the design of modern blown glass artworks stress beauty of form and artistic concept in terms of artistic expression forms, reflecting modern artistic pursuit and taste through free expression technique.

- Constructive: Blown glass art has provided a space for performance and expansion to meet human's functional and aesthetic needs for spatial environment, with rich technique of expression and application form, and it has provided more possibilities for human creation with it's own material properties. Natural light effect or lighting enable blown glass art to produce a unique visual aesthetics, which forms a mutual coordination and balance with the psychological effects produced in the environment space, constructing an atmosphere of spatial environment meeting people's needs.

With the development of construction techniques, the internal space of building has been continuously expanded with increasingly complicated functions. The interior of building not only needs to be beautified, but also needs a scientific division to fully meet people's spiritual and cultural, behavioral, psychological and physiological needs, etc; interior design is generally becoming an important discipline derived from architectural design, and can exist independent from architectural design; and the design of blown glass interior furnishings thus become the finishing touch in the interior design process without doubt.

From the religious thought transmitted from the stained glass painting in the European medieval church to the simple and practical modern technology, and till the present multicultural era, glass art tends to meet people's work and living space requirements with more varied expressive forms, enriching people's perception of art, enabling people to feel the visual changes produced by glass art in different spatial orientation and light source. And it is the new exploration and creation in spatial decoration design. 
In the current 21 st century, the tide of multi-culture will undoubtedly promote the arts and design toward a new and broad future. Blown glass art will develop toward a new and higher direction no matter it is applied in artistic creation or architectural space in terms of design performance style or process technology, playing an important role in building the ideal home for human survival, leaving more perfect artistic crystallization for our era and history. Dale Chihuly, a master in the field of international blown glass, found that glass has the characteristics unmatched by any other materials when using as a creative medium, he became involved in the glass industry widely. As early as 1965 , as a student specialized in interior design and architecture, he was already fascinated by the art of glass blowing. The early furnishing works of Chihuly contains abundant natural spirit, establishing the most direct integration between nature and art. He has already reached the perfect position and gained the joy of life from early furnishings with abundant knowledge. Over four decades, Chihuly's art style gradually revealed in the glass sculpture. From the simple glassware to the complicated furnishing artworks for both indoor and outdoor, his blown glass works are known for the best combination of color and lines. His works have a wide variety, such as the tea table decorations designed for small environment, and the big ones will appear in the form of sculpture groups; or exist in largescale indoor and outdoor furnishings in coordination with specific engineering facilities. Chihuly and his team have created a lot of blown glass artworks. And they have created some exciting new works while inheriting and carrying forward the existing work patterns. The creation of these furnishings has enhanced this artist's sensitivity in architectural art and his confidence in the interaction between natural light and glass, and continuously to stimulate his interest in transparent and translucent effects.

And that has changed the American glass studio movement fundamentally, expanding his work environment from solitude to a group with spirit of collaboration and division of labor, and in view of this, he has always been praised by people. His contributions transcend national borders, and his achievements have influenced contemporary glass art no matter in the studio glass movement, or in the entire glass processing field. The creative team led by him has brought about a comprehensive development to the complicated sculpture art and the enjoyment of beauty to the world, making him a leader in the field of blown glass. Dale Chihuly is not limited to the creation of small precious items, but to travel throughout the sculpture kingdom with freedom. In fact, from the twentieth century till now, blown glass technology which is applied to the environmental art creation created by him has been renowned in the world.

\section{DIVERSIFIED SOCIETY PROVIDES A FREE DEVELOPMENT SPACE FOR BLOWN GLASS ARTISTIC FURNISHINGS}

- Modern society providers a tolerant attitude to traditional artistic culture, so designers may use and develop the tradition, and absorb different cultures;
- Commercial society renders the international characteristic to blown glass artistic furnishings, and the expansion of freedom degree will inevitably impact the close national culture. The process of national wealth to be shared by the world makes the blown glass artistic furnishings continuously present a new look;

- Individual behavior of artists and designers can not represent the overall trend of the times, but their ideas and works reflect the spirit of time of modern blown glass furnishings from all sides.

Free space provides an excellent environment for the artistic concept conveying, and the development of creative thinking of modern blown glass artistic furnishings tends to reflect more and more of its independence and the side of diversity. Form the perspective of personalized needs, modern blown glass artistic furnishings are no longer one or several fixed appearances and styles, but have integrated social, human, psychological, physical, economic, technical, material and artistic and other factors, developing in an unprecedented multiple coexistence way, adapting to different cultural groups with colorful appearance and creating a colorful life.

All the artistic achievements are relying on human's discovery and application of the unique material of glass. Technology development is continuously improving the craftsmanship level of blown glass, human's artistic creativity and its constructive feature for environment and architectural design, which is an important driving force for blown glass art to develop toward new space.

Chinese modern blown glass art is in the starting phase in the interior furnishings design, and in the phase of learning and imitation, inheritance and innovation simultaneously. Our artists not only explore in the wide range of world culture, but also increasingly set their sights on our own cultural ideas, in order to increase cultural connotation and characteristics of the work. Along with more inspiration and absorption of foreign arts and crafts, the in depth exploration of our own culture, and finding inspiration continuously in national traditions and modern life, it is believed that China's modern blown glass artistic interior furnishings can be further developed, and find their own position.

As a separate category of art, and in the starting period of Chinese glass art, glass shall stand on its own feet based on its own unique spiritual and artistic features in the world. Only in this way, can China's modern glass art develop healthily, have the foundation for survival and a place to stand. Glass artworks are exquisitely carved, flawless, pure, bright and colorful with high ornamental value and infinite artistic charm. Along with China's economic development, people's living standards have improved constantly, and domestic demand for glass artworks is constantly expanding. Moreover, with the acceleration of world economic integration process, the export routes of glass artworks will be more extensive and smooth. China occupies a significant advantage in terms of raw material supply, culture background and human resources for glass artworks. Expansion of China's glass artwork exports will be inevitable. 
And these are favorable conditions for the development of China's glass art industry. After the current situation and problems are cleared, feasible measures must be formulated to take advantage of favorable conditions for the development of China's glass arts.

\section{REFERENCES}

[1] Decoration [J]. Chinese Decoration Magazine, June 2005

[2] Dai Shufeng. Glass Art [M]. Tsinghua University Press, June 2004

[3] blownglass.www. China.cn [Z]

[4] blownglass. alibaba.com.cn [Z] 